\title{
Estado, escolas e famílias: públicos escolares e regulação da educação*
}

\author{
Fátima Antunes \\ CIEDd/Universidade do Minho \\ Virgínio Sá \\ CIEDd/Universidade do Minho
}

Introdução: breve enquadramento da pesquisa

Os resultados que aqui se partilham condensam algumas das conclusões de um projecto de investigação que se desenvolveu no terreno ao longo dos anos lectivos de 2005/2006 a 2008/2009 ${ }^{1}$ e que, genericamente, inscrevemos nos complexos processos de (multi)regulação da educação (Barroso, 2003a). $\mathrm{Na}$ senda de diversos autores, nesta investigação considera-se a regulação no campo da educação como (i) o conjunto dos mecanismos postos em acção para produzir a congruência dos comportamentos, individuais e colectivos e mediar os conflitos sociais, bem como limitar as distorções que possam ameaçar a coesão social, incluindo, em particular, (ii) a defi-

* Esta investigação foi apoiada pelo Centro de Investigação em Educação (CIEd) da Universidade do Minho.

1 O relatório detalhado do projecto de investigação em apreço encontra-se actualmente em vias de publicação com o título Públicos escolares e regulação da educação: lutas concorrenciais na arena educativa. nição de padrões e regras que estabeleçam o quadro para o funcionamento das instituições; entendemos assim que, (iii) nos sistemas complexos, o quadro da regulação é plural e resulta da interacção de múltiplos processos e actores (cf. Boyer, 1987; Aglietta, 1997; Dale, 1997; Barroso, 2006).

Para Barroso, "num sistema social complexo (como o sistema educativo) existe uma pluralidade de fontes, finalidades e modalidades de regulação em função da diversidade dos actores implicados (das suas posições, dos seus interesses e das suas estratégias)". Dessa forma, "a coordenação, o equilíbrio ou transformação do funcionamento do sistema educativo resultam antes da interacção dos múltiplos dispositivos reguladores" (Barroso, 2003b, p. 10). Esse autor distingue três modalidades de regulação baseadas em alianças distintas entre actores decisivos no campo educativo: uma regulação burocrática, edificada ao longo do processo de desenvolvimento dos sistemas educativos e que corresponderia a uma aliança entre o Estado e os professores; uma regulação baseada no mercado, visível em muitos países, sobretudo anglófonos, a partir dos anos de 1980 e que envolveria 
uma aliança do Estado com os pais, sobretudo da classe média; uma regulação baseada na comunidade, ensaiada em processos desenvolvidos ao nível local, por exemplo em Portugal nos últimos anos, e que seria sustentada por alianças entre os professores e famílias (Barroso, 2003b, p. 11-12).

Segundo Dale (1997, p. 279; 2005), a natureza e o significado da regulação terão sofrido mudanças nos últimos anos: por um lado, a sua forma ter-se-á transformado, passando do que tem sido apreendido como uma forma de regulação determinada por regras, que opera a jusante do funcionamento, por meio dos inputs - isto é, das condições (normas, orientações, recursos, políticas...) fornecidas ao sistema educativo -, para uma forma de regulação determinada por objectivos que actua a posteriori, assente em determinadas realizações (outputs) do sistema. Mas a mudança terá agora alcançado um outro patamar, em que a base da regulação reside nos resultados (outcomes) determinados para o sistema. Assim, os resultados requeridos do funcionamento dos sistemas educativos devem ser traduzidos em desempenhos/produtos/saídas imediatas exibidos pelas escolas e perante os quais estas serão avaliadas. Dale argumenta que a agenda supranacional para educação e formação se constitui já como parte desta última forma de regulação e que as avaliações do tipo dos estudos PISA representam uma ilustração desse mecanismo de controlo de resultados. ${ }^{2}$

A investigação evoluiu ao longo de três fases, cada uma delas abrangendo distintos conjuntos de unidades de observação e com recurso a dispositivos

2 Trata-se do Programme for International Student Assessment (PISA), desenvolvido pela OCDE a partir de 2000 para medir as competências dos jovens de 15 anos; não se pretende avaliar aquisições escolares, mas os desempenhos ante tarefas, definidos aqueles pelos técnicos da OCDE como expressão de competências importantes. As primeiras avaliações PISA, em 2000, envolveram uma amostra de jovens de 15 anos de 32 países (28 Estados-membros da OCDE, bem como a Rússia, Lituânia, Brasil e Liechtenstein) e incidiram majoritariamente sobre o domínio da leitura e compreensão da escrita. técnico-metodológicos também diferenciados. Num primeiro momento, de âmbito mais alargado, tomou-se como campo de observação um conjunto das escolas com oferta de ensino secundário no território em estudo (concelho do norte de Portugal, convencionalmente designado Vila Formosa). ${ }^{3}$ Foram considerados sete dos 11 estabelecimentos existentes à época do início da pesquisa (2005); excluíram-se duas escolas profis-

3 O sistema de ensino não superior português verifica a seguinte estrutura: (i) educação de infância (nível pré-escolar), dos 3 aos 6 anos; (ii) ensino básico, 9 anos (universal, gratuito e obrigatório): $1^{\circ}$ ciclo, com 4 anos, entre os 6 e os 10 anos; $2^{\circ}$ ciclo, de 2 anos, dos 10 anos aos 12 anos; $3^{\circ}$ ciclo com 3 anos, entre os 12 anos e os 15 anos; (iii) ensino secundário, ciclo de 3 anos, dos 15 anos aos 18 anos. O estudo centrou-se em escolas com oferta de ensino secundário, nível que, no sistema brasileiro, corresponde ao ensino médio. O ensino obrigatório em Portugal foi, recentemente, alargado de 9 para 12 anos.

Entre o $1^{\circ}$ e o $9^{\circ}$ ano do ensino básico a avaliação dos alunos é contínua e interna, da responsabilidade dos respectivos docentes e seus órgãos próprios; no final do $9^{\circ}$ ano do ensino básico há exames nacionais, com provas elaboradas por serviços da administração central, às disciplinas de português e de matemática; as pontuações obtidas nesses exames contribuem para as classificações finais dos alunos segundo uma fórmula definida pela tutela. Ao longo e no final do ensino secundário, os estudantes dos cursos vocacionados para o prosseguimento de estudos devem realizar exames nacionais a algumas disciplinas, elaborados pelos serviços centrais. É com base nos resultados desses exames nacionais que são elaborados, pela comunicação social, os rankings das escolas secundárias (públicas e privadas). Nos cursos tecnológicos, profissionais e de educação e formação do ensino secundário e para os estudantes que não pretenderem prosseguir para o ensino superior, a avaliação é contínua e interna e da responsabilidade dos docentes e seus órgãos próprios. Os diplomados desses cursos que desejarem aceder ao ensino superior terão ainda que realizar exames a uma ou duas disciplinas, de acordo com as provas específicas definidas pelos cursos e estabelecimentos do ensino superior a que pretendam candidatar-se. Para uma percepção global da organização do sistema educativo português, ver o Anexo 1, ou aceder ao site http:// www.gepe.min-edu.pt. 
sionais, um externato e uma escola de ensino artístico por se entender que, quer os seus públicos, quer o seu âmbito de acção introduziam aspectos e atribuíam-lhes propriedades que obrigariam a controlar e discutir questões que manifestamente não figuram na primeira linha de prioridades desta pesquisa; entretanto, mais recentemente abriu uma outra escola privada com ensino secundário. Nessa fase, foram inquiridos, por meio de entrevista semiestruturada, os responsáveis de sete escolas de Vila Formosa (os presidentes de conselhos executivos ou os directores pedagógicos no caso de se tratar de escolas públicas ou privadas, respectivamente), o coordenador de área educativa e uma ex-estudante de um dos estabelecimentos de ensino. Num segundo momento, reduziu-se o campo de observação a três escolas, para permitir um aprofundamento e contextualização da análise. ${ }^{4}$ Nessa fase do estudo foi aplicado um inquérito por questionário a uma amostra de encarregados de educação das três escolas seleccionadas (responderam 815 inquiridos). Por último, a recolha de informação centrou-se numa única escola e foi suportada por entrevistas semiestruturadas a docentes com distintos cargos e a estudantes de diferentes cursos. Esta escola (Escola Alfa) foi seleccionada porque apresentava uma con-

${ }^{4}$ Inicialmente estava previsto que, nessa fase do estudo, a amostra deveria integrar três escolas públicas e uma escola privada. Contudo, os contactos ensaiados para negociar a inclusão da escola privada não obtiveram resposta afirmativa por parte da escola seleccionada. As escolas públicas foram seleccionadas em função das suas características em termos de localização e oferta curricular. Assim, a escola Kapa tinha à altura a quase totalidade dos seus alunos $(96,2 \%)$ em cursos gerais/científico-humanísticos; na escola Delta mais de um terço dos alunos $(36,6 \%)$ frequentavam cursos tecnológicos; a escola Alfa mostrava um perfil com a maioria dos alunos inscritos (cerca de 80\%) na fileira designada de prosseguimento de estudos (Antunes \& Sá, 2006). Por sua vez, a escola Delta, sendo central, está situada numa das saídas da cidade, a cerca de mil e quinhentos metros do centro, enquanto as escolas Kapa e Alfa se encontram no centro do centro urbano e separadas entre si por aproximadamente quinhentos metros (as designações das escolas são convencionais). fluência de diversidade de características: acolhimento de públicos diversificados (incluindo os dos cursos tecnológicos), boa posição nos rankings nacionais, ${ }^{5}$ procura superior à oferta em determinados cursos, escolhida pela elite e facilidade de acesso por parte dos investigadores.

A investigação desenvolvida procurou esclarecer, entre outras, as seguintes questões: como intervêm, em certos domínios relevantes, as políticas educativas, os processos escolares e as estratégias das famílias para produzir um envolvimento educacional diferenciado e uma desigual distribuição e apropriação de bens educativos para distintos segmentos da população? Como lidam as escolas com as novas condições que enquadram as suas actividades, nomeadamente no que respeita à gestão da diversidade dos públicos escolares? Que orientações e práticas são produzidas em áreas em que se jogam mecanismos de fabricação do(s) público(s) de uma escola, por exemplo, a organização das matrículas, a formação das turmas e organização dos horários, a gestão dos recursos (humanos e materiais), dos currículos e programas? Em que medida a organização e a publicitação dos rankings dos resultados dos exames condicionam os processos de gestão interna das escolas? Quais as estratégias desenvolvidas pelas famílias para explorar as novas condições decorrentes da (suposta) deslocação do controlo do produtor para o consumidor? Quais as consequências de tais processos na distribuição e apropriação dos bens educacionais (na democratização cultural e social) actualmente em Portugal?

\footnotetext{
${ }^{5}$ Entre as sete escolas secundárias incluídas na nossa amos-
} tra, no período abrangido pela investigação (2005-2009), a escola Alfa ocupou sempre a primeira posição nos rankings nacionais elaborados a partir dos resultados dos exames do $12^{\circ}$ ano. Nesse período, em nível nacional, de entre as cerca de seiscentas escolas com oferta de ensino secundário, a escola Alfa ocupou uma posição próxima do $30^{\circ}$ lugar. No mesmo ranking nacional, as restantes seis escolas apresentaram posições relativamente diversificadas, oscilando entre $60^{\mathrm{a}}$ e a $300^{\mathrm{a}}$ posições. 


\section{A gestão da diversidade de públicos escolares: o agrupamento dos alunos em turmas}

No âmbito do ensino secundário, de entre as diferentes estratégias susceptíveis de serem mobilizadas pelas famílias para assegurar distinção, destacam-se as várias modalidades de escolha, legalmente contempladas ou informalmente admitidas, com destaque para a escolha do bom curso, a escolha das boas opções, a escolha da boa escola e, não menos importante (embora menos visível), a escolha da boa turma. Com frequência essas várias escolhas funcionam de modo cumulativo e tendem a produzir efeitos interactivos (que se potenciam mutuamente), resultando daí, não raras vezes, claras desigualdades de oportunidades.

No quadro das políticas, orientações e critérios reguladores do agrupamento dos alunos em turmas, e considerando a problemática da gestão da diversidade dos públicos escolares (e da fabricação da excelência), ${ }^{6}$ uma das questões mais polémicas e mais debatidas, embora com menos incidência em Portugal, prende-se à velha dicotomia heterogeneidade versus homogeneidade e a correlativa existência ou não de turmas de nível e o seu impacto no desempenho e aspirações dos alunos. Efectivamente, o agrupamento dos alunos em função das suas competências e aptidões ${ }^{7}$ constitui um dos temas mais controversos da literatura educacional e, não obstante o enorme volume e diversidade da investigação no domínio, não há na comunidade académica e educacional dados adquiridos que possam sustentar a tomada de decisão quanto às opções em aberto. Desde logo porque quando se trata de avaliar as consequências das opções entre o agrupamento dos alunos baseado no princípio da homogeneidade ou da heterogeneidade, as modalidades de o materializar podem ser bastante diversas, além de os referentes utilizados para ajuizar do sucesso das

${ }^{6}$ Utilizamos aqui a expressão "fabricação da excelência" por analogia com a metáfora da "fabricação das hierarquias de excelência" desenvolvida por Perrenoud (1996).

${ }^{7} \mathrm{O}$ que na literatura anglo-saxónica se denomina por ability grouping. distintas opções poderem também ser dificilmente harmonizáveis. Por exemplo, investigações diversas mostram que o princípio da homogeneidade, quando aplicado interturmas e intraturmas, produz consequências bastante distintas.

No quadro de uma curta revisão da literatura sobre o impacto do modo de agrupamento dos alunos sobre as suas "aquisições" e "atitudes", Duru-Bellat e Mingat (1997) sustentam que uma política orientada para a defesa do "interesse geral" deveria conduzir à opção pela promoção das classes heterogéneas, dado que, nessas circunstâncias, “os alunos de nível inferior ao nível da sua turma 'ganham' muito mais do que ‘perdem' os alunos situados acima do nível médio dos seus condiscípulos" (p. 787). Contudo, a promoção do "interesse geral" nem sempre é fácil de harmonizar com a satisfação dos interesses particulares dos distintos públicos escolares que pressionam os decisores no sentido de escolhas organizacionais que melhor respondam à sua busca de vantagens competitivas.

Também Gomes (2005, p. 296-297), num texto em que aborda o complexo desafio de construir uma escola de qualidade para todos, baseando-se em algumas sínteses da literatura sobre o "efeito turma", considera igualmente que "a escolha da escola e o agrupamento dos alunos por turma podem ter sérias implicações para o sucesso e a equidade". Mais adiante, o mesmo autor afirma que "dentro de cada escola pode haver diferenças no processo de ensino-aprendizagem conforme, entre outros aspectos, a composição das turmas, a alocação de professores e de recursos e, ainda, os processos educativos no âmbito de cada sala de aula" (p. 300). Em relação à controvérsia homogeneidade/ heterogeneidade, Gomes (idem, p. 302), baseando-se em Riordan (2004), afirma que, "segundo a maior parte da pesquisa, a formação de turmas homogéneas aumenta o hiato de aproveitamento entre os mais e os menos 'fortes"'.

Apesar das aparentes vantagens em constituir turmas de modo que faça sobressair "o arco-íris na sala de aula", Cortesão (1998, p. 7), referindo-se à realidade portuguesa, observa que a existência de "turmas boas", "turmas médias" e "turmas-problema" 
constitui uma realidade tão frequente que se corre o risco de a naturalizar e, por consequência, deixar de ser representada como uma "situação problemática". Contudo, defende a mesma autora, a constatação da existência de uma sobrerrepresentação, numa mesma turma, ora de alunos "bons", ora de alunos "maus", não resulta, necessariamente, de uma decisão intencional de beneficiar uns e prejudicar outros: "O que acontece com mais facilidade é optar-se por certos critérios de organização, sem que se tenha consciência dos efeitos uniformizantes e selectivos que eles poderão ter" (idem, p. 7-8).

No que à constituição das turmas diz respeito, em Portugal as orientações da administração educativa raramente revestem uma natureza impositiva e tendem a ser relativamente genéricas, deixando, portanto, espaços para a autorregulação, para a definição de orientações próprias que reflictam a(s) cultura(s) político-pedagógica(s) das escolas, incluindo os valores e concepções de justiça social que subscrevem. Se, por um lado, dada a sua inserção sociogeográfica e as condicionantes decorrentes da rede escolar negociada, as escolas secundárias "herdam" um determinado público escolar, por outro lado, o modo como arrumam os alunos do mesmo ano de escolaridade pelas diferentes turmas constitui, em grande medida, um campo de decisões escolares ${ }^{8}$ modelizáveis em função das doutrinas político-pedagógicas subscritas pelos órgãos a quem cabe definir e operacionalizar os princípios a que deve obedecer aquela arrumação.

No processo de agrupamento dos alunos por turmas (do mesmo ano), é conveniente distinguir três situações básicas:

i) a constituição das turmas dos alunos que frequentam uma determinada escola pela primeira vez, normalmente iniciando um novo ciclo;

${ }^{8}$ É certo que em alguns casos, nomeadamente no ensino secundário e nas escolas de menor dimensão, as margens de discricionariedade são bastante estreitas, uma vez que as opções dos alunos em termos de curso/agrupamento quase determinam a sua alocação a uma determinada turma. ii) a constituição das turmas no início do secundário;

iii) e a constituição das turmas dos anos seguintes à primeira matrícula.

Dos três casos tipificados, é sobretudo nos dois primeiros que se abre espaço para a definição de novos arranjos que espelhem a filosofia própria de cada escola, nomeadamente no que concerne à questão da homogeneidade/heterogeneidade das turmas. Uma análise global ao conjunto dos trechos das entrevistas em que os nossos entrevistados se reportam a aspectos relacionados com a constituição de turmas permite, num primeiro registo, pôr em evidência a aparente recusa das turmas de mesmo nível, pelo menos como opções deliberadas da escola. Contudo, esse discurso da recusa das turmas homogéneas convive com um conjunto de práticas muito generalizadas que, em muitos casos, anula a eficácia daquele discurso. Por um lado, o respeito pelo que "vem de trás": "As turmas [...] vêm para aqui em grupo, se a turma for boa a turma é boa, se a turma for complicada a turma é complicada"; 9 por outro lado, a heterogeneidade para a maioria e algumas turmas "arranjadinhas": "Repare, o que a maior parte das escolas fazem é isso [constituir turmas mais ou menos heterogéneas], fazem as turmas assim e depois preocupam-se em fazer duas turmas 'arranjadinhas"." ${ }^{10}$

Apesar de o princípio da continuidade, traduzido no "manter o que vem de trás", constituir o procedimento dominante, também registámos um caso de uma "política" que aponta num sentido diametralmente oposto:

Aliás, mantemos uma política das turmas também, de que nunca mantenho a turma do $9^{\circ}$ ano. Se vierem 15 alunos duma turma [de outra escola] para aqui, nós dividimos em

\footnotetext{
9 Trecho da entrevista realizada à directora da escola Beta.
} Para preservar o anonimato das escolas, adoptamos designações convencionais.

10 Trecho da entrevista realizada ao director da escola Kapa. 
dois blocos. Não queremos uma turma no $10^{\circ}$ ano que fique praticamente [...] Não, desfazemos os grupos, dividimos o grupo. ${ }^{11}$

No ensino secundário, a existência de turmas de nível pode ter raízes diferentes. A acção cumulativa da escolha do agrupamento, aliada à escolha das disciplinas de opção, contribui para uma certa homogeneidade intracursos e para o acentuar das diferenças intercursos. Contudo, a elitização de certas turmas, dentro do mesmo agrupamento, pode ainda ser reforçada através da escolha das opções. Esta escolha, como factor de selectividade, pode assumir dois tipos de configurações: i) opções que dão acesso aos cursos mais procurados e em que, por isso, a procura ultrapassa a oferta, sendo a selecção feita com base nas notas; ii) opções que são escolhidas não tanto porque dão acesso a cursos específicos, mas porque podem introduzir algum factor de distinção e facilitar a integração em turmas com um ethos académico mais acentuado (por exemplo, escolher a disciplina de matemática num curso de ciências sociais).

Como consequência, e por acção do efeito cumulativo das várias escolhas, as turmas apresentam diferenças significativas de rendimento traduzidas nas boas e nas más turmas. Aparentemente, tais diferenças são associadas ao mérito individual, que a escola se limita a sancionar, ocultando-se que uma parte dessa "excelência" (bem como o insucesso dos excluídos) é fabricada (no sentido usado por Perrenoud, 1996) pela forma como se regula o acesso aos bens educativos e pelo modo como se operacionaliza esse acesso, com a própria instituição escolar a jogar também o seu papel, seja por omissão, reproduzindo decisões alheias, seja pelas decisões organizacionais que toma. Efectivamente, como também Cortesão (1998) pôs em evidência, os "argumentos" habitualmente invocados pelas escolas para justificar as suas decisões em relação ao modo de constituição das turmas, apesar de aparentemente anódinas (ou até sustentáveis em racio-

11 Trecho da entrevista realizada ao director da escola Sigma. nalidades válidas e legítimas), podem, nos contextos específicos em que são mobilizadas, configurar-se como instrumentos de homogeneização, fechamento, segregação, selectividade e rotulagem.

\section{Vias sinuosas: interesses e desvantagens em co(a)lisão}

A administração dos recursos humanos no seio de uma escola é uma tarefa complexa e delicada, com lugar em múltiplos níveis e órgãos que medeiam conflitos de interesses e pontos de vista. Aliás, a mediação e a negociação revelam-se processos-chave para organizar essa força de trabalho sui generis, criada também por força do particular ofício que desenvolve. ${ }^{12}$

Quando procuramos compreender como se organiza o trabalho dos docentes numa escola, ainda que apenas num aspecto limitado - o complexo processo de atribuição de professores às diferentes categorias de alunos -, encontramos um amplo espectro de orientações e procedimentos, geralmente combinados, procurando acomodar as múltiplas racionalidades, prioridades e solicitações que devem ser consideradas:

Como é que é feita a distribuição? Os professores manifestam as suas preferências, há uma ficha que diz: "não tem carácter obrigatório...” Isto porque a gestão deve ter em conta essa satisfação na docência, isto é muito importante. Depois, efectivamente, há todos aqueles que preferem o básico, vão para o básico. Todos aqueles que preferem o secundário vão para o secundário; [...] se num determinado grupo ficarem professores que já não sejam precisos para o secundário, efectivamente vão para o básico, mesmo não

12 Fazendo uma análise comparativa entre as escolas e os hospitais, em ambos os casos organizações complexas, Sarmento (2000, p. 159) afirma: "Nos dois casos são as pessoas que são 'processadas', mas nas escolas são os projectos sociais (a cultura e a estrutura social) e a inserção dos seres humanos em formação nesses projectos que estão no centro da acção concreta. É aqui que reside a incontornável implicação política da acção em contexto escolar". 
o preferindo. [...] Passa por essa questão da graduação profissional. $^{13}$

No decurso da pesquisa foi possível apreender instâncias, processos e configurações de processos associados à atribuição e distribuição de recursos humanos a categorias de alunos. A coexistência, não raro dilemática, entre injunções e princípios de acção afigura-se algo marcada pela prevalência do imperativo da eficácia associada à presença importante de práticas orientadas para a construção da confiança e da proximidade, entre os alunos e com os docentes, ou justificadas pelo interesse geral.

Os professores devem dar continuidade, os anos terminais devem ser atribuídos aos professores [do quadro da escola]. Estão na lei, mas também são internos, nós tivemos capacidade para fazer essas alterações. [...] Esses horários devem ser os primeiros a ser atribuídos, as turmas terminais do $12^{\circ}$ ano, ano de exame, devem ser sempre os primeiros horários a atribuir. Há uma preocupação a esse nível. [...] De facto tentamos conjugar, de maneira a que todos fiquem contentes. ${ }^{14}$

Assim, a complexidade e a mediação constituem pedras de toque dos processos e dos níveis a que ocorrem, salientando a negociação e a construção de compromissos entre solicitações, critérios, interesses e actores e a diversidade de configurações, entre e até intraescolas, como traços maiores dos processos estudados em torno da atribuição de professores e turmas. Cabe ainda destacar que a natureza desses compromissos se afigura em boa medida precária e por demais desequilibrada, frequentemente trilhando sinuosas vias de direccionamento de vantagens cumulativas, procurando dar o melhor aos melhores, fazendo o possível por todos. Esta acentuada orientação meritocrática constitui-se indisfarçavelmente cúmplice de um certo

${ }^{13}$ Trecho de entrevista com a presidente do conselho executivo da escola Gama.

14 Trecho de entrevista com a presidente do conselho executivo da escola Beta. darwinismo social impulsionado por opções sociais e culturais que recentemente vincaram clivagens existentes de poder e recursos.

Os nossos professores do quadro [...] eu tenho um quadro na ordem dos $80 \%$, esses $80 \%$ são necessários para assegurar o secundário. Para tirar daí 10\% de professores que preferem o básico e que já me permitem cumprir a taxa que está estipulada pelo projecto educativo de professores do quadro que têm que estar no básico. Eu fico no início do ano com as turmas todas do secundário, com os professores distribuídos, mesmo com aqueles atrasos, o secundário anda sempre; a partir de 16 de setembro estavam os professores todos colocados. Onde é que tivemos o problema das tais três semanas [de atraso], que depois tivemos que colmatar? Foi em algumas disciplinas do básico, não todas. ${ }^{15}$

Ao mesmo tempo, ganharam claro relevo as conexões entre indicadores institucionais de estratificação do conhecimento/curricular e a estrutura social de distribuição de bens, recursos e poder marcada por desigualdades sociais cavadas a montante e a jusante da instituição escolar, na estrutura social de origem e nas instituições de ensino superior e estratificação ocupacional e profissional.

Assim, como tentativa de síntese, poder-se-ia defender, no actual estado de conhecimento e reflexão, que esta pesquisa aponta como principal mecanismo de regulação nesta actividade de distribuição de recursos humanos por categorias de alunos, internamente às escolas, a mobilização de uma diversidade de instâncias (colegiais e individuais, organizacionais e institucionais), acompanhada da pluralidade de critérios; essa configuração, que pode apresentar âmbitos distintos, chega a garantir um certo e necessário confronto, negociação e compatibilização de interesses. Os diversos critérios e instâncias que são activados e combinados tendem a agregar algumas orientações que logram alcançar um apreciável consenso ao nível pedagógico (sublinhando o que é interpretado

15 Trecho de entrevista com a presidente do conselho executivo da escola Gama. 
como interesse geral; por exemplo, a prioridade aos alunos com exame ou à continuidade pedagógica), à invisibilidade sociológica das consequências da sua aplicação (a prioridade aos estudantes das fileiras mais bem-sucedidas, o que pode bem configurar o favorecimento de interesses particulares). Desse modo, os efeitos desse mecanismo saldam-se por um apreciável desequilíbrio de interesses e categorias de alunos beneficiados e desfavorecidos em simultâneo com o aparente consenso de que são alvo entre as seis escolas em que explorámos essa dimensão do nosso estudo.

Esse consenso repousa de modo decisivo em condições que ligam a instituição escolar com a totalidade societal; assim, essas três dimensões (conexões ou convergências) estudadas parecem contribuir significativamente para a consolidação daquele mecanismo de regulação (diversidade de instâncias e critérios/ negociação e mediação/compatibilização precária e desequilibrada de interesses):

(i) satisfação profissional intrínseca dos docentes (dependência dos alunos) + adesão/ofício de aluno socialmente marcados + escolarização/pedagogia padronizada (aluno-ideal);

(ii) preferências/interesses dos docentes (laborais, profissionais, de poder e estatuto institucional)/interesses de segmentos sociais mais poderosos;

(iii) prestígio institucional/conhecimento de acesso e posse restritos e concorrenciais (exames).

\section{Hierarquias de excelência: alguns factores subjacentes à escolha da escola pelos pais}

Num contexto marcado pela complexa reconfiguração dos processos de (multi)regulação (Barroso, 2003a) na arena educativa, que se desenvolve em paralelo com uma crescente procura (desencantada) da educação, é fundamental questionar se (e em que medida) a "democratização quantitativa", traduzida no acesso a mais educação para todos, tem contribuído para a "democratização qualitativa", ou se, pelo con- trário, tem antes induzido formas de "democratização segregativa" (Merle, 2002), traduzida na "translação" e "recomposição" das desigualdades.

As políticas de (livre) escolha da escola pelos pais, componente essencial dos processos de refundação das relações entre "produtor" e o "consumidor" dos bens educativos, têm-se prestado a leituras diversas, umas enfatizando o seu potencial democratizador, outras denunciando a sua agenda oculta orientada para a (re)elitização do sistema (Ball, 1995). Compreender o modo como diferentes categorias de pais organizam as suas "hierarquias de excelência", pelos "argumentos de escolha" que privilegiam, constituiu um dos objectivos da investigação em discussão. Os dados empíricos em que nos baseamos para desenvolver a nossa análise foram recolhidos por meio de um inquérito por questionário aplicado a uma amostra constituída por 815 encarregados de educação, distribuídos por três escolas secundárias (escola Alfa, escola Kapa e escola Delta) do concelho de Vila Formosa. Para recolhermos a resposta dos nossos inquiridos, recorremos a uma pergunta fechada de resposta múltipla. Foram discriminadas 11 alternativas de resposta complementadas com a opção "Outro", solicitando-se aos inquiridos que, se fosse o caso, o especificassem (Ver Quadro I).

Dada a natureza necessariamente parcelar do material empírico em que se sustentou este percurso de indagação, não é obviamente possível avançar com "conclusões". Registámos, contudo, algumas "tendências" que consideramos oportuno salientar. Desde logo, importa destacar que começa a se delinear uma observação no sentido de que, quanto a alguns aspectos relacionados com a escolha, encontramos diferenças com alguma expressão entre os respondentes das diversas escolas, embora menos entre os segmentos de respondentes (pais/encarregados de educação) com diferentes graus de escolaridade, o que é algo inesperado e para o que ensaiamos algumas possíveis pistas de leitura.

Em todo o caso, os respondentes de diversos graus de escolaridade mostram sensibilidades diversas, com os encarregados de educação escolarizados ao nível 
Quadro I - Factores que influenciaram os pais/EE na escolha da escola $(n=815)$

\begin{tabular}{|l|c|c|c|c|c|c|c|c|}
\hline & \multicolumn{2}{|c|}{ Muito Imp. } & \multicolumn{2}{c|}{ Importante } & \multicolumn{2}{c|}{ Pouco Imp. } & \multicolumn{2}{c|}{ Sem Imp. } \\
\cline { 2 - 11 } & Freq $^{\underline{a}}$ & $\%$ & Freq $^{\underline{a}}$ & $\%$ & Freq $^{\underline{a}}$ & $\%$ & Freq $^{\underline{a}}$ & $\%$ \\
\hline Proximidade do local de habitação & 153 & 18,8 & 318 & 39,0 & 209 & 25,6 & 91 & 11,2 \\
\hline Proximidade do local de trabalho & 53 & 6,5 & 173 & 21,2 & 257 & 31,5 & 274 & 33,6 \\
\hline Ter o curso pretendido & 543 & 66,6 & 204 & 25,0 & 28 & 3,4 & 13 & 1,6 \\
\hline $\begin{array}{l}\text { Outros irmãos/amigos frequentarem } \\
\text { a escola }\end{array}$ & 127 & 15,6 & 237 & 29,1 & 164 & 20,1 & 229 & 28,1 \\
\hline O ambiente de disciplina da escola & 290 & 35,6 & 385 & 47,2 & 78 & 9,6 & 19 & 2,3 \\
\hline O elevado grau de exigência da escola & 224 & 27,5 & 417 & 51,2 & 107 & 13,1 & 24 & 2,9 \\
\hline O prestígio da escola & 247 & 30,3 & 402 & 49,3 & 106 & 13,0 & 23 & 2,8 \\
\hline $\begin{array}{l}\text { A escola preparar bem os alunos para } \\
\text { os exames }\end{array}$ & 411 & 50,4 & 297 & 36,4 & 48 & 5,9 & 16 & 2,0 \\
\hline A qualidade das instalações & 199 & 24,4 & 411 & 50,4 & 111 & 13,6 & 37 & 4,5 \\
\hline A abertura da escola aos pais & 187 & 22,9 & 402 & 49,3 & 134 & 16,4 & 31 & 3,8 \\
\hline $\begin{array}{l}\text { A posição da escola nas listas } \\
\text { ordenadas publicadas nos jornais }\end{array}$ & 87 & 10,7 & 271 & 33,3 & 250 & 30,7 & 111 & 13,6 \\
\hline Outro (especifique) & 8 & 1,0 & 3 & 0,4 & 4 & 0,5 & 0 & 0,0 \\
\hline
\end{tabular}

igual ou superior ao ensino secundário a enfatizar, de forma progressivamente mais intensa, a importância de preparar bem para os exames, a exigência atribuída à escola, ou a atenuar a relevância da qualidade das instalações, a valorização dos rankings das escolas e a sua preferência em função do ambiente de disciplina, perante outros segmentos de respondentes. Não se pode, contudo, concluir que a escala de prioridades e de valorização (ao nível de importante e muito importante) de factores-base para a escolha apresenta divergências de monta entre os segmentos com diversos graus de escolaridade. Isto é, a partir dos dados agregados das três escolas em que se desenvolveu esta dimensão do estudo, afigura-se-nos problemático definir hierarquias de excelência baseadas em padrões de escolha estruturados a partir das variáveis de caracterização da população, com particular referência aos níveis de escolaridade concluídos. Com efeito, para um número significativos de argumentos de escolha, é possível encontrar adeptos com idênticos níveis de entusiasmo em todo o espectro de encarregados de educação.

No entanto, entre as escolas encontramos expressivas divergências de frequências de respostas quanto à importância atribuída a alguns factores de escolha da escola em que o jovem estudante se encontrava. Os dados recolhidos permitem-nos constatar que a escola Alfa, quando comparada com as outras duas escolas estudadas, parece exercer uma maior capacidade de atracção sobre os encarregados de educação que tendem a expressar maior adesão a "factores de escolha" como o elevado grau de exigência, o preparar bem para os exames, o prestígio da escola e a sua posição nos rankings publicados pela comunicação social e revelam menor sensibilidade a factores como a proximidade. Seja porque exerce uma acção magnética sobre os encarregados de educação que mais valorizam determinadas propriedades escolares, seja porque o filtro que utiliza para resolver o problema da procura que excede a oferta retém alunos cujos encarregados de educação valorizam aquelas mesmas propriedades, o resultado final parece ser uma maior concentração dos encarregados de educação que, além (e para além) de uma escolaridade média mais elevada, aderem a uma hierarquia de excelência que ressalta propriedades mais centradas no "produto", derivadas sobretudo das aparentes qualidades acadé- 
micas da escola. Por sua vez, os nossos respondentes da escola Delta são, comparativamente com os outros inquiridos, bastante mais atentos aos condicionalismos da proximidade, enquanto a exigência ou o prestígio têm relativamente menos peso na sua decisão, sendo o ambiente de disciplina da escola um factor importante na ponderação da decisão de uma esmagadora maioria de respondentes. A escola Kapa ocupa uma posição intermédia no conjunto dos argumentos de escolha considerados.

Essa pista de indagação deve, contudo, ser apresentada com bastante prudência porque, como referimos antes, os dados em que sustentamos esta leitura sofrem de limitações que previnem proposições mais assertivas. Como tem sido reconhecido por outras investigações (Adler et al., 1989; Gewirtz et al., 1995), identificar "razões" de escolha da escola a partir de uma lista ordenada ("abordagem do menu"), além de pressupor um actor social guiado por uma hiper-racionalidade, esconde ainda um potencial efeito de enviesamento induzido pelas alternativas (não) consideradas. Acresce ainda que, no nosso caso, o questionário foi aplicado na parte final do ano lectivo, exigindo do inquirido a reconstituição de um procedimento que, na melhor das hipóteses, tinha tido lugar cerca de um ano antes (alunos do $10^{\circ}$ ano), embora para a maioria tivesse ocorrido mesmo com dois a três anos de distância (alunos do $11^{\circ}$ e $12^{\circ}$ anos de escolaridade). A dilucidação de algumas das incertezas com que nos deparámos impõe, portanto, o retorno ao campo, espera-se agora que munidos de um arsenal técnico-metodológico mais apto a captar não apenas os ditos mas também os interditos. Os silêncios podem ser ruidosamente eloquentes.

\section{"Explicações": ${ }^{16}$ quando o desempenho mascara a desigualdade}

Em consonância com outras investigações, também os dados da pesquisa que apresentamos mostram que se recorre a "explicações" quer por dificuldades em pro-

\footnotetext{
${ }^{16} \mathrm{Na}$ terminologia brasileira, cursinhos.
}

gredir, quer porque se pretende elevar o desempenho. Essas duas situações revelam facetas distintas do sistema de ensino: num caso, estaremos eventualmente perante obstáculos que se prendem à criação de condições de aprendizagem e progresso no currículo para todos (e cada um) dos alunos; no segundo caso, defrontaremos antes as reacções de certos sectores de beneficiários do sistema de ensino ao facto de este fazer progredir e capacitar um número crescente de jovens como potenciais candidatos e aspirantes a estudos e diplomas de níveis mais elevados. Nesta segunda alternativa, quando se verifica uma situação de restrição absoluta (em que o número de candidatos excede o de lugares disponíveis) ou relativa (quando a escassez ocorre em relação a certas preferências e não à totalidade de vagas) de oportunidades, aumenta, na mesma ordem de grandeza, a concorrência entre os aspirantes. Assim é, em qualquer dos casos, a realização da escola de massas, ou escola para todos, nas condições actuais, que está em questão no "caso" do "mercado de explicações".

Dos 806 pais/encarregados de educação que forneceram respostas a esta questão, $488(60,5 \%)$ estavam a recorrer ou já tinham recorrido a explicações para os respectivos educandos. Por seu lado, 318 (39\%) indicaram que nunca tinham recorrido a explicações. Dos 483 inquiridos que reconheceram ter recorrido a explicações, 226 indicaram que estavam a fazê-lo pela primeira vez no ano lectivo em que foi aplicado o questionário.

\section{Gráfico 1}

Número de pais que recorreram a explicações

$$
(n=806)
$$

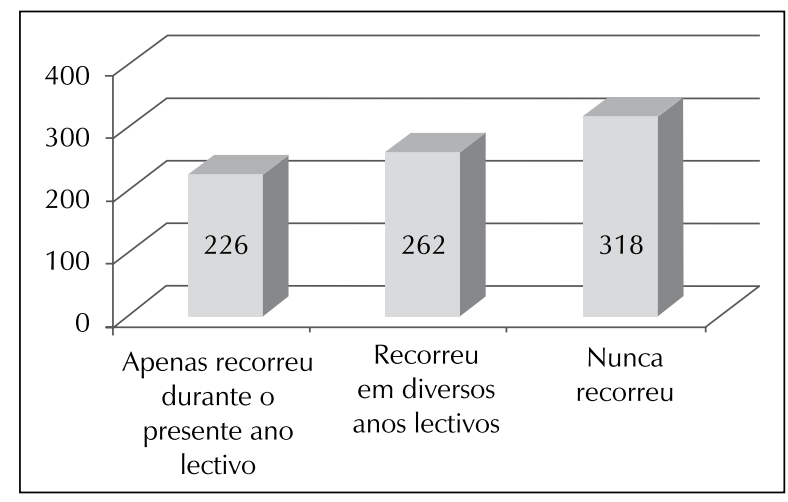


Menos de quatro em cada dez agregados domésticos envolvidos com o ensino secundário referem nunca ter mobilizado recursos adicionais para prover ou elevar o desempenho requerido pelo sistema de ensino aos seus filhos; olhar este fenómeno como manifestação quer dos défices da pedagogia perante seus públicos, quer dos excessos das lutas concorrenciais e dos processos de distinção (Bourdieu, 1979), traz à colação a interpelação dos processos e mecanismos de regulação da produção de resultados escolares e do acesso ao ensino superior.

Vislumbramos, a partir de diversas grelhas de leitura teórico-conceptuais disponíveis e mobilizadas (Bernstein, 1996; Bourdieu, 1998; Perrenoud, 2000, entre outros), elementos de regulação institucional em que se associam, por um lado, igualdade formal, padronização curricular e diferenciação pedagógica não intencional oficiais com, por outro lado, respostas ao desempenho exigido sustentadas em recursos privados. Estas reacções por parte dos jovens e agregados domésticos reduzem os danos e mantêm a provável insatisfação resultante em níveis compatíveis com a legitimação do sistema à custa, por um lado, da sustentação parcialmente privada dos resultados certificados pelo sistema e, por outro, da distribuição desigual dos bens educacionais em termos de formação e diplomas e dos rendimento, poder e estatuto a que aqueles dão acesso. A relativa desarticulação entre pedagogia e avaliação é aqui o nó que permite a mobilização de recursos privados externos ao dispositivo pedagógico oficial (Bernstein 1996) e o reconhecimento e certificação, por parte daquele, de desempenhos cujo processo de formação tem lugar para além e apesar das condições institucionais que propicia para esse fim.

Nesse sentido, o conhecimento educacional é distribuído, mesmo no seio da escola pública, segundo modalidades que combinam, em âmbitos porventura insuspeitos, a privatização e mercadorização das condições e dos recursos em que o seu acesso e aquisição são regulados. A presença maciça das práticas em que estes dependem ou se apoiam na capacidade aquisitiva dos indivíduos indicia processos de regulação estruturalmente favoráveis ou vulneráveis a formas de funcionamento que premeiam ou penalizam assimetricamente os públicos em função da sua condição económica e social.

No entanto, um outro ângulo do fenómeno precisa ser analisado: o da contextualização e compreensão da prática e dos praticantes de "explicações" no quadro mais amplo em que ele tem lugar, isto é, de uma competição regulada pelo Estado que, como autoridade pública, detém a capacidade de, através de políticas (sociais/educativas), estabelecer os termos dos confrontos dos interesses sociais, as formas da sua negociação e compatibilização (provisória) e, dessa forma, estabelecer o contexto da regulação, isto é, o quadro em que os diversos actores, instituições e grupos sociais (re)agem (Lenhardt \& Offe, 1984; Boyer, 1987; Dale, 1997; Barroso, 2003a). Nessa perspectiva, trata-se de uma situação em que, sendo o ensino superior de acesso condicionado por numerus clausus em cada uma das suas fileiras, o filtro é estabelecido por um mecanismo que, assentando exclusivamente nos níveis de desempenho em determinadas disciplinas certificados pelas avaliações interna e externa, centra a competição na obtenção de vantagens nesses mesmos parâmetros. Como se entende, o desenvolvimento de estratégias de maximização dos desempenhos certificados, por parte de jovens e suas famílias, é o corolário que decorre de uma situação de concorrência regulada por um mecanismo em que esse é o parâmetro decisivo em termos da concretização de expectativas e projectos de posicionamento social. Do leque de consequências da mesma combinatória de elementos faz parte a competição das escolas por alunos academicamente "rentáveis" ou dos alunos pela escolha da escola, da turma ou dos professores ou ainda dos alunos por estabelecimentos de ensino (alegadamente em regra privados) onde a atribuição de classificações elevadas seria mais "liberal" do que nas escolas públicas.

Na sequência das evidências empíricas recolhidas e das análises teóricas disponíveis, bem como de outros factos conhecidos pela experiência ou estudados na literatura, queremos defender o argumento-hipótese de que a opção do Estado por aquele mecanismo de 
regulação da competição é consoante, senão filiado, ao espírito de liberalização e desregulação em favor de soluções que favorecem:

(i) o acesso a direitos básicos e bens essenciais (como a educação e os bens culturais) dependente da capacidade económica, poder e estatuto;

(ii) a libertação ou promoção activa de novas áreas e oportunidades de operação de actividade mercadorizada e lucrativa;

(iii) a construção da educação como bem individual de acesso concorrencial. $\mathrm{O}$ mesmo mecanismo de regulação da competição pelo acesso ao ensino superior evidenciou já um cortejo de consequências de que é possível destacar a criação de:

a) um tremendo mercado de "explicações";

b) as desigualdades associadas à combinação de capital económico e cultural que essa prática implica;

c) uma significativa concorrência e fenómenos de segregação (ou, segundo alguns, polarização) entre alunos, turmas, escolas;

d) a acumulação de favorecimentos por uns e desvantagens por outros no acesso a recursos importantes em educação (tempo, espaço, professores, ambiente estimulante...) organizados e distribuídos no interior das escolas e enquadrados também por outras normas internas ou nacionais;

e) um nicho de mercado para escolas conhecidas simultaneamente pela sua selectividade de acesso (decorrente do nível das mensalidades associado ao posicionamento social dos seus frequentadores) e "liberalidade" na atribuição de classificações "inflaccionadas" ante a generalidade das escolas públicas.

Se é reconhecida a associação de tais desenvolvimentos à influência de pressupostos e respostas de teor neoliberal no estado português (Afonso, 2008;
Neto-Mendes, 2008), é ainda forçoso considerar a perspectiva de que a autoridade pública tem à sua disposição outros instrumentos reguladores da competição por lugares no ensino superior e que essas outras opções teriam consequências distintas em termos da construção do contexto de confronto e negociação entre os diversos interesses sociais e de (re)acção dos diferentes actores.

\section{Trabalhar para o ranking e imagens de polarização}

Paralelamente, nos testemunhos analisados, se reconhece o impacto da publicitação dos rankings elaborados com base nos resultados dos exames nacionais na reconfiguração das lógicas, orientações, prioridades e processos mobilizados pelas escolas nos momentos em que efectivam determinadas escolhas organizacionais, denunciando, simultaneamente, o seu carácter de "publicidade enganosa":

Os rankings não traduzem a qualidade da escola por muitíssimas razões. Uma escola pública, por exemplo, que apenas apresente a exame meia dúzia de alunos do $12^{\circ}$ ano de duas disciplinas, colocá-la no topo do ranking, não tem qualquer sentido, nomeadamente se ela está a ser comparada com escolas públicas, ou privadas, que apresentam a exame 300 ou 400 alunos de todas as disciplinas. ${ }^{17}$

A publicitação de diversas "ligas" nacionais de escolas constitui uma pressão adicional, mediante a qual as escolas, segundo os seus responsáveis, mobilizam parte dos seus recursos materiais e simbólicos para alimentar uma imagem favorável e o marketing capaz de a potenciar. Além disso, a seriação de escolas afigura-se importante na medida em que induz ou condiciona decisões em situações particulares relacionadas sobretudo com escolas que queiram trabalhar para o ranking:

${ }^{17}$ Excerto da entrevista ao director pedagógico da escola Ómega. 
A questão dos rankings é assim: qualquer escola que queira trabalhar para o ranking (trabalhar para o ranking é uma expressão que penso que hoje em dia é comum) [...] tem obviamente de assumir algumas alterações de filosofia da própria escola, alterações de projecto da escola. ${ }^{18}$

Se me permitissem cair em cima de alunos mal comportados, se me permitissem escolher os docentes, se me permitissem escolher os alunos [...] eu garanto que esta escola, ou qualquer outra escola, estaria em $1^{\circ}$ lugar, [...] nós não ligamos porque chegamos à conclusão de que a certa altura não vale a pena ligar, porque as pessoas que fazem esses rankings estão em gabinetes e não sabem o que é que se passa na escola. ${ }^{19}$

Assim, a atribuição de professores a anos curriculares/turmas, a organização de turmas, a realização de matrículas, a orientação ou pressão sobre os alunos para frequentarem aulas particulares (explicações), a selecção dos alunos propostos a exame pela escola (alunos internos) constituem "provavelmente justificações realistas para algumas situações muito perto do topo do ranking" (director pedagógico da escola Ómega).

Nessa medida, a construção de listas ordenadas parece ter, no que respeita à estratificação das escolas, impacto sobretudo quanto à fabricação de imagens contrastadas: as escolas da moda, por um lado; as escolas refugo, por outro; a imensa maioria das escolas em posições intermédias ficaria relativamente intocada quanto ao particular aspecto da imagem. No entanto, o ranking produz efeitos sociais (polarização de escolas e alunos), políticos (concentração de poderes e de recursos em grupos, categorias sociais), ideológicos (promoção de mecanismos de escolha, de concorrência e de mercado) e morais (afirmação de valores de mérito e sucesso individual como base para o vínculo e a ordem social). As "ligas" nacionais de escolas parecem então constituir sinais exteriores

18 Excerto da entrevista ao director pedagógico da escola Ómega.

${ }^{19}$ Excerto da entrevista ao presidente do conselho executivo da escola Delta. das formas e estratégias imprimidas às lutas culturais concorrenciais em torno da educação, sobretudo marcadas pela assertividade e influência de fracções da classe média, a avaliar pela argumentação de alguns analistas; esboçam-se, deste modo, novos contornos das lutas culturais no nosso país e alguns elementos ainda fragmentários que podem vir a integrar o novo modo de regulação. A ser assim, que posicionamentos podem ser encontrados nas actuações do Estado, das escolas, dos professores e das famílias?

\section{Facetas de democratização. Formar uma elite e educar um povo}

As entrevistas realizadas na terceira fase do estudo a alunos e a professores dão a conhecer em altíssimo relevo duas áreas problemáticas que afectam a vida quotidiana da escola e manifestam tendências marcantes na construção da educação, do sistema educativo e da profissão docente: por um lado, a crescente presença e influência de formas de relações sociais derivadas do imperativo de competitividade (a injunção para conquistar as primeiras posições em lutas concorrenciais por recursos, neste caso entre indivíduos e instituições), no âmbito quer da atribuição de classificações aos alunos, quer da elaboração das identidades das instituições; por outro lado, a incontornável tensão aberta pela formação de distintos mundos sociais, académicos e cognitivos, interactivos e relacionais, numa mesma escola. ${ }^{20} \mathrm{Uma}$ e outra tendências são relevantes para as questões que exploramos: que educação é distribuída a quem e por quem? Com que consequências? Como se (re)constrói a (des)igualdade nesta distribuição e como participam e reagem os diferentes actores (designadamente o Estado, as escolas, as famílias) perante esses processos, seus resultados e implicações?

Nestas entrevistas (realizadas na escola Alfa), os testemunhos destacam, com mais acuidade que em

${ }^{20}$ O título do capítulo "Formar uma elite e educar um povo" é uma paráfrase do título de um texto escrito por Steve Stoer em 1986. 
outras observações, como o imperativo da competitividade, lado a lado com a integração institucional de novos públicos (a coesão social) constituem vectores estruturantes de expectativas das nossas sociedades ante a educação que (também) as fabrica. Os relatos incidem sobre aspectos críticos do actual processo de escolarização ao nível secundário, prendendo-se quer com pressões e dilemas enfrentados por docentes, alunos e pela escola, como actor colectivo, em torno do acto de avaliar, quer com a circunstância recentemente generalizada de acolhimento de públicos cujas características socioculturais e académicas desafiam as missões institucionais historicamente sedimentadas e, consequentemente, a experiência e as expectativas profissionais colectivas e individuais dos docentes naqueles estabelecimentos. As duas dinâmicas enunciadas - a emergência de pressões crescentes com fontes diversas em torno do acto de avaliar, acentuadas quando se trata de públicos mobilizados para a consecução das elevadas classificações exigidas para o acesso aos cursos de ensino superior mais disputados, por um lado, bem como a presença de novos públicos mais numerosos nas salas de aulas de nível secundário - cruzam-se aparentemente com maior acutilância quando crescem a heterogeneidade sociocultural e as assimetrias de desempenho académico dos públicos acolhidos. Nessas situações dir-se-ia que as escolas, os professores e os alunos experimentam como problemas, desafios e fracassos pedagógicos, profissionais e pessoais, individuais e colectivos as tensões, dilemas e dificuldades sociopolíticos que atravessam o sistema educativo e social.

Pressões, tensões, dilemas e perplexidades em torno do acto de avaliar permeiam os relatos de professores: ora os instrumentos que concebem, ora os critérios que mobilizam para aferir a informação recolhida, ora os juízos que emitem e as classificações que atribuem se encontram submetidos a perturbadores jogos de forças e influências cujas condições de recepção e desenvolvimento parecem alimentar turbulências e perplexidades sem necessariamente estimular respostas e propostas capazes de enfrentar as dificuldades e os desafios colocados:
Se está em causa a obtenção de uma média para concorrer à universidade então aí a luta é... [...] Então eles vêm aqui e veem as pautas e começam a comparar: "Então, mas Psicologia teve esta nota e a Português tem 17? Isto não pode ser, isto aqui, alguma coisa está mal, a professora está a dar notas muito baixas", não é? Não pode ser... Depois vão atacar Área de Projecto e Educação Física [...] ou então tenho problemas mesmo de revisão de provas no final do ano. É o que eu estou a contar neste final do ano, que foi bastante acidentado porque temos alunos, na minha turma, vários alunos com pretensões a Medicina e tenho a certeza absoluta de que, se os professores não derem as notas que de facto são pretendidas por aqueles alunos, vai haver recursos. [...] Exactamente, o pai pede que a nota que lhe foi atribuída pelo conselho de turma [seja revista] e o conselho de turma vai, portanto, reconsiderar o 17 que deu ao aluno e ver se não é possível dar um 18, na disciplina de Português ou na disciplina de Educação Física, e claro que o pai não necessita de argumentar muito. ${ }^{21}$

Paralelamente, a partir de 2005, o Ministério da Educação português lançou a Iniciativa Novas Oportunidades, que incluía o objectivo de certificar com o ensino secundário 650 mil jovens até 2010. Nesse contexto, e num ritmo de premência crescente, as escolas de ensino secundário regular foram chamadas a escolarizar públicos até aí excluídos. Essa injunção, em si mesma desejável, para além de legítima, como efectivação do direito social e humano à educação, foi parcamente acompanhada desde o início do processo pela autorresponsabilização, plena ou partilhada, do Estado. Mais especificamente, para o debate que neste momento interessa desenvolver, queremos sugerir que aquela distanciação do Estado para um papel de "direcção estratégica", controlo e monitorização, típica de mandamentos da proposta Nova Gestão Pública (Hartley, 2003), pode bem representar um descompromisso com certas dimensões das suas próprias políticas. Tal afastamento é patente, a nosso ver, no que aparece como um surpreendente e preocupante voluntarismo na condução das políticas. Assim, pode-

\footnotetext{
${ }^{21}$ Trecho de uma entrevista de um docente da escola Alfa.
} 
se compreender que uma fonte de tensão avulte nos testemunhos recolhidos junto de docentes na escola Alfa: a interacção com jovens "que andam na escola e não têm postura de alunos".

A impreparação e a desmotivação são experimentadas ao lidar com jovens cujos perfil sociocultural e aspirações se encontram desconectados das propostas de actividades, das relações com os saberes que aquelas requerem e das formas de interacção que constituem a experiência, o saber tácito e explícito e o quadro de exercício profissional destes docentes:

De facto é um trabalho mais árduo [leccionar a alunos dos cursos profissionais]. E nós apanhamos aqui meninos de facto que não querem saber, [...] alguns não querem saber e até são pacíficos. São alunos que estão ali, mas há outros que são aborrecidos, são mal-educados, [...] pronto, e isso desgasta imenso a gente: está numa turma, e depois vai para outra com o mesmo comportamento, e depois vai para outra com o mesmo comportamento, e isso ao fim de um dia de trabalho é terrível, não é? É desmotivante.

Por exemplo, uma minha colega o ano passado desesperou com o profissional, "Eu nunca mais quero o profissional!” É verdade, ela saía das aulas a chorar. ${ }^{22}$

Por seu lado, os alunos salientam o olhar negativo de que se sentem alvo:

Não sei qual o problema, mas é por serem cursos profissionais parece que são menores ou inferiores aos outros, não percebo, não sei qual é o problema. ${ }^{23}$

Os testemunhos dos jovens dão conta dos diversos imbróglios e nós cegos que defrontam. Estigmatizados por sucessivas gerações de políticas educativas inspiradas na tríade de vocacionalização do insucesso, desvalorização do trabalho e da educação profissional e exacerbação do academismo da fileira científicohumanística, os percursos de dupla certificação

${ }^{22}$ Trechos de entrevistas de docentes da escola Alfa.

${ }^{23}$ Trecho de uma entrevista de um aluno da escola Alfa (cursos profissionais). (escolar e profissional) sofrem a desqualificação escolar resultante de serem vistos como percursos para insucedidos, bem como se ressentem da desvalorização a que o trabalho, sobretudo manual, é sujeito na sociedade e na escola portuguesas.

Ainda há alunos que dizem: "Ai, curso profissional...", pronto, inferiorizam as pessoas. [...] Torneios que há na escola, actividades, geralmente participam, agora o que há é uma certa discriminação por parte de alguns professores e de alguns alunos sabendo que é do ensino profissional, que aqueles que são do ensino profissional, aí é que pode haver alguma discordância. [...] Não é uma forma de procurar, é uma forma deles nos olhar. Olham de maneira diferente, sabendo que somos do ensino profissional, é isso que acontece. [...] fazem comentários... [...] do tipo "Ah, são do ensino profissional, são rebeldes", é logo. ${ }^{24}$

No entender dos nossos entrevistados, carregam um estereótipo com carga depreciativa que os homogeneíza e lhes cola atributos de outras épocas. Julgam-se depositários de uma herança que os penaliza, através da cegueira que impede aqueles que os classificam de se relacionarem com eles de acordo com os jovens e estudantes que sentem que são e as opções e os projectos que constituem a sua realidade actual.

É este o lado avesso do acesso à educação, articulado nas vozes de alunos e professores. Uns falam da sua dependência de recursos pedagógicos e de acção com que não se encontram capacitados, os outros acusam a perplexidade de não se reverem nos modos como se acham posicionados na instituição em que esperam ser educados. Duas pistas de questionamento nos são deixadas: como assume o Estado o seu compromisso com as condições de escolarização dos públicos a que alarga a sua acção educativa? Como promove a capacitação institucional do sistema, em termos de procedimentos e mecanismos institucionais, de recursos organizacionais, de dispositivos pedagógicos e repertórios de acção dos docentes para

24 Trecho de uma entrevista de um aluno da escola Alfa (cursos profissionais). 
que a comunicação e as estratégias de aprendizagem relevantes possam ter lugar?

\section{Considerações finais. Formar uma elite e escolarizar uma geração: educação universal no modo concorrencial?}

Este breve périplo pelos dados provenientes da pesquisa apresentada permite-nos apontar algumas das modalidades pelas quais são produzidas (des)vantagens diferenciadas para certas categorias de públicos escolares; neste processo estão envolvidas medidas de política educativa, lógicas e cursos de acção organizacional, actuações e estratégias dos jovens e suas famílias. Por um lado, as intervenções do Estado, como política social, criam o terreno onde os actores desenvolvem cursos de interacção mediante recursos, interesses e (proto)alianças passíveis de serem actualizados; por outro lado, as lógicas, opções e os cursos de acção organizacional das escolas combinam-se com as orientações da tutela de formas complexas e nem sempre coincidentes; por sua vez, jovens e famílias actuam a partir não apenas de projectos, como de recursos e constrangimentos muito distintos.

Assim:

(i) há famílias que desenvolvem estratégias muito claras para retirar vantagens acrescidas do funcionamento e dos bens disponibilizados pelo sistema de ensino; o conhecimento do sistema, a mobilização de recursos como a pressão grupal, capital social ou manipulação ou contorno das regras de funcionamento são alguns dos meios a que podem recorrer; em todo o caso, trata-se de obter uma distribuição de recursos favorável aos seus filhos: os melhores professores, horários, turmas... O agrupamento de estudos, o curso e, dentro deste, a disciplina de opção podem constituir outras tantas escolhas capazes de influenciar o acesso àqueles meios. De acordo com a informação colectada, estes cursos de acção tendem a ser protagonizados por pais que dispõem de um capital escolar e cultural elevado e, desta forma, procuram assegurar para os seus filhos o privilégio relativo possível na prossecução de uma "boa ou melhor" educação;

(ii) por sua vez, as escolas actuam, em dadas situações, segundo princípios e escolhas que se afiguram muito débeis para garantir que a distribuição de (des)vantagens em educação não se torne mais cavada por acção ou omissão da própria instituição e seus agentes. A adopção do princípio da continuidade (o "respeito pelo que vem de trás") para a formação de turmas, sendo legítima de um ponto de vista pedagógico imediato, pode, por exemplo, prolongar para dentro da escola efeitos ou continuidades de assimetrias que atravessam a distribuição espacial das populações (rural/urbano; bairro social, popular/urbanização de classe média mais ou menos abastada...). Assim, potenciais implicações sociológicas e educacionais daquele princípio (homogeneidade intraturmas associada à discrepância interturmas quanto a resultados escolares, comportamento e origem social, entre outros aspectos) são em regra conhecidas, mas frequentemente desvalorizadas, o que fragiliza a acção da escola perante aquelas assimetrias;

(iii) ainda a atribuição de professores a grupos de alunos pode beneficiar os estudantes mais bem-sucedidos do ponto de vista académico, agora com base em orientações pouco consistentes da tutela combinadas com opções organizacionais e dos professores que envolvem constrangimentos associados ao exercício da profissão e do trabalho docentes;

(iv) mesmo que mostrando sensibilidades diversas, não se pode, contudo, concluir que a escala de prioridades e de valorização de factores-base para a escolha da escola apresenta divergências de monta entre os segmentos de encarregados de educação com diversos graus de escolaridade. No entanto, entre as escolas encontramos expressivas divergências de 
frequências de respostas quanto à importância atribuída a alguns factores de escolha da escola em que o jovem estudante se encontrava;

(v) olhar o fenómeno das "explicações" como manifestação quer dos défices da pedagogia ante os seus públicos, quer dos excessos das lutas concorrenciais e dos processos de distinção traz à colação a interpelação dos processos de formação e certificação dos desempenhos escolares e de regulação do acesso ao ensino superior. Se, no primeiro caso, é a relativa desarticulação entre pedagogia e avaliação que permite o reconhecimento e certificação de desempenhos cujo processo de formação tem lugar para além e apesar das condições institucionais que são propiciadas, na segunda alternativa o desenvolvimento de estratégias de maximização dos desempenhos certificados, por parte de jovens e suas famílias, é o corolário que decorre de uma situação de concorrência regulada por um mecanismo em que esse é o parâmetro decisivo em termos da concretização de expectativas e projectos de posicionamento social;

(vi) a criação de listas ordenadas de escolas com base nos resultados em exames nacionais de conclusão do ensino secundário tem, no entendimento dos nossos entrevistados, o efeito de criar categorias de mérito e estigma para algumas escolas, mas também de induzir cursos de acção de evitamento ou exclusão de estudantes academicamente menos desejáveis;

(vii) ao alargar a sua acção educativa, sob o signo de um posicionamento "menor" para os novos públicos, o Estado permite, se não promove, que crie raízes e se estabeleça o fatalismo das expectativas negativas sobre "rebeldes do ensino normal". Assim, descurando o seu compromisso com a capacitação institucional, organizacional e dos profissionais para responder de forma confiante e bem-sucedida às necessidades educacionais desses públicos, o
Estado contribui para criar as condições para que desafios, problemas e dificuldades sejam remetidos e enfrentados no foro individual.

A informação colectada e a sua análise conduzem sobretudo ao levantamento de questões sobre como está a ser regulado o acesso aos, e a distribuição dos, recursos educacionais pelas diferentes categorias de públicos escolares. Aparentemente, por um lado, os processos de formação de turmas, atribuição de professores e horários, de escolhas de agrupamento, curso e escola constituem diferentes áreas de actuação permeáveis à produção de (des)vantagens em favor daquelas categorias de públicos academicamente mais prometedoras. Por outro lado, os modos como são formados e certificados os desempenhos escolares no ensino secundário e como é regulado o acesso ao ensino superior têm fomentado uma dependência crescente de investimentos económicos importantes das famílias para o acesso e o sucesso em algumas das fileiras desse nível de ensino. Como afirmámos antes, no seio do projecto de escolarização maciça e prolongada de toda uma geração perfila-se a criação de clubes ou nichos exclusivos onde a acumulação de recursos e benefícios escolares, culturais e simbólicos tem lugar. Se, por um lado, a confirmar-se, esse facto aponta para elementos de um novo modo de relação da estrutura (e da ordem) social com a educação, também, e em consequência, será importante compreender qual o grau e frequência em que aquelas "excepcionalidades" ocorrem e com que implicações para os públicos envolvidos.

\section{Referências bibliográficas}

ADLER, Michael, PETCH, Alain; TWIDIE, Jack. Parental Choice and Educational Policy. Edinburgh: Edinburgh University Press, 1989.

AFONSO, Almerindo J. As explicações no contexto neoliberal do mercado educacional. In: COSTA, Jorge A.; NETO-MENDES, António; VENTURA, Alexandre, Xplika: investigação sobre o mercado das explicações. Aveiro: Universidade de Aveiro, 2008. p. 26-34.

AGLIETTA, Michel. Régulation et Crises du Capitalisme. Paris: Éditions Odile Jacob, 1997. 
ANTUNES, Fátima; SÁ, Virgínio (2006). Estado, escolas e famílias: públicos escolares e regulação da educação. In: MOREIRA, A. F.; PACHECO, J. A.; CARDOSO, S.; SILVA, A. C. Actas do VII Colóquio sobre Questões Curriculares (III Colóquio LusoBrasileiro), Globalização e (des)igualdades: os desafios curriculares. Braga: CIEd. p. 1198-1212.

BALL, Stephen J. Mercados educacionais, escolha e classe social: o mercado como uma estratégia de classe. In: GENTILI, Pablo (Org.). Pedagogia da exclusão: crítica ao neoliberalismo em educação. Petrópolis: Vozes, 1995. p. 196-227.

BARROSO, João (Org.). A escola pública: regulação, desregulação, privatização. Porto: ASA, 2003a.

O Estado e a educação: a regulação transnacional, a regulação nacional e a regulação local. In: (Org.). A regulação das políticas públicas de educação: espaços, dinâmicas e actores. Lisboa: Educa, 2006. p. 41-70. Les mutations de "l'État éducateur": de la raison visible de l'État à la "main invisible" du marché. Conferência apresentada ao Séminaire Printemps. Porto: Faculdade de Psicologia e Ciências da Educação, 3 e 4 de abril de 2003 (texto policopiado), 2003b.

BERNSTEIN, Basil. A estruturação do discurso pedagógico: classe, códigos e controle. Petrópolis: Vozes, 1996.

BOURDIEU, Pierre. La distinction: critique sociale du jugement. Paris: Minuit, 1979.

Escritos de educação (antologia organizada por Maria Alice Nogueira e Afrânio Catani). Petrópolis: Vozes, 1998.

BOYER, Robert. La Théorie de la Régulation: une analyse critique. Paris: La Découverte, 1987.

CORTESÃO, Luíza. O arco-íris na sala de aula? Processos de organização de turmas: reflexões críticas. Lisboa: Instituto de Inovação Educacional, 1998.

DALE, Roger. A globalização e a reavaliação da governação educacional. Um caso de ectopia sociológica. In: TEODORO, António; TORRES, Carlos A. (Org.). Educação crítica e utopia:perspectivas para o século XXI. Porto: Afrontamento, 2005. p. 53-69.

. The State and the governance of education: an analysis of the restructuring of the State-education relationship. In: HALSEY, A. H.; LAUDER, Henry; BROWN, Philippe; WELLS, Anne S. (Org.). Education: culture, economy and society. New York: Oxford University Press, 1997. p. 273-282.

DURU-BELLAT, Marie; MINGAT, Alain. La constitution de classes de niveau dans les collèges: les effets pervers d'une pratique à visée égalisatrice. Revue Française de Sociologie, v. XXXVIII, p. 759-789, 1997.
GABINETE DE ESTATÍSTICA E PLANEAMENTO DA EDUCAÇÃO/INSTITUTO NACIONAL DE ESTATÍSTICA (GEPE/ INE). 50 Anos de Estatísticas da Educação - Volume I. Lisboa: GEPE/INE, 2009.

GEWIRTZ, Sharon; BALL, Stephen J.; BOWE, Richard. Markets, choice and equity in education. Buckingham: Open University Press, 1995.

GOMES, Candido. A escola de qualidade para todos: abrindo as camadas da cebola. Revista Ensaio, v. 13, n. 38, p. 281-306, 2005.

HARTLEY, David. Education as a global positioning device: some theoretical considerations. Comparative Education, v. 39, n. 4, p. 439-450, 2003.

LENHARDT, Gero; OFFE, Claus. Teoria do Estado e política social. In: OFFE, Claus (Org.). Problemas estruturais do Estado capitalista. Rio de Janeiro: Tempo Brasileiro, 1984. p. 10-53.

LIMA, Licínio C. Topografia complexa das decisões em educação. In: ESTRELA, Albano; FERREIRA, Júlia (Ed.). A decisão em educação. Lisboa: AFIRSE/FPCE/UL, 1998. p. 3-13.

MERLE, Pierre. La democratisation de l'enseignement. Paris: La Découverte, 2002.

NETO-MENDES, António. A regulação das explicações entre o Estado e o mercado. In: COSTA, Jorge A.; NETO-MENDES, António; VENTURA, Alexandre. Xplika: investigação sobre o mercado das explicações. Aveiro: Universidade de Aveiro, 2008 p. $85-102$.

PERRENOUD, Philippe. La construción del éxito y del fracasso escolar. Madrid: Morata, 1996.

. Pedagogia diferenciada: das intenções à acção. Porto Alegre: Artmed, 2000.

RIORDAN, Cornelius. Equality and achievement. 2. ed. New Jersey: Pearson Prentice Hall, 2004.

SARMENTO, Manuel. Lógicas de acção nas escolas. Lisboa: Instituto de Inovação Educacional, 2000.

STOER, Stephen R. Formar uma elite ou educar um povo? Jornal da Educação, n. 91, p. 22, 1986.

FÁTIMA ANTUNES, doutora em educação, na área de especialização de sociologia da educação pela Universidade do Minho e professora associada no Departamento de Ciências Sociais da Educação do Instituto de Educação da Universidade do Minho. Publicações recentes: Políticas educativas para Portugal, anos 80/90: o debate acerca do ensino profissional na escola pública (Lisboa: Instituto de Inovação Educacional, 1988); Políticas edu- 
cativas nacionais e globalização. Novas instituições e processos educativos. O subsistema de escolas profissionais em Portugal (1987/1998) (Braga: Universidade do Minho, 2004); Nova ordem educacional, espaço europeu de educação e aprendizagem ao longo da vida. Actores, processos e instituições. Subsídios para debate (Coimbra: Almedina, 2008). É investigadora efectiva do Centro de Investigação em Educação do Instituto de Educação da Universidade do Minho no domínio de Democratização e regulação da educação: políticas, processos e práticas. E-mail: fantunes@ ie.uminho.pt

VIRGÍNIO SÁ, doutor em educação, na área de organização e administração escolar, pela Universidade do Minho, é professor associado no Departamento de Ciências Sociais da Educação do Instituto de Educação da Universidade do Minho e membro da Comissão Directiva do Centro de Investigação em Educação do referido Instituto. Publicações recentes: Racionalidades e práticas na gestão pedagógica: o caso do director de turma (Braga: Instituto de Inovação Educacional, 1997); A participação dos pais na escola: uma abordagem sociológica e organizacional (Braga: Centro de Investigação em Educação da Universidade do Minho, 2004). Participa actualmente no projecto Democratização e regulação da educação: políticas, processos e práticas.E-mail: virsa@ie.uminho.pt

Recebido em junho de 2010 Aprovado em agosto de 2010

\section{Anexo 1}

\section{Estrutura do Sistema Educativo Português}
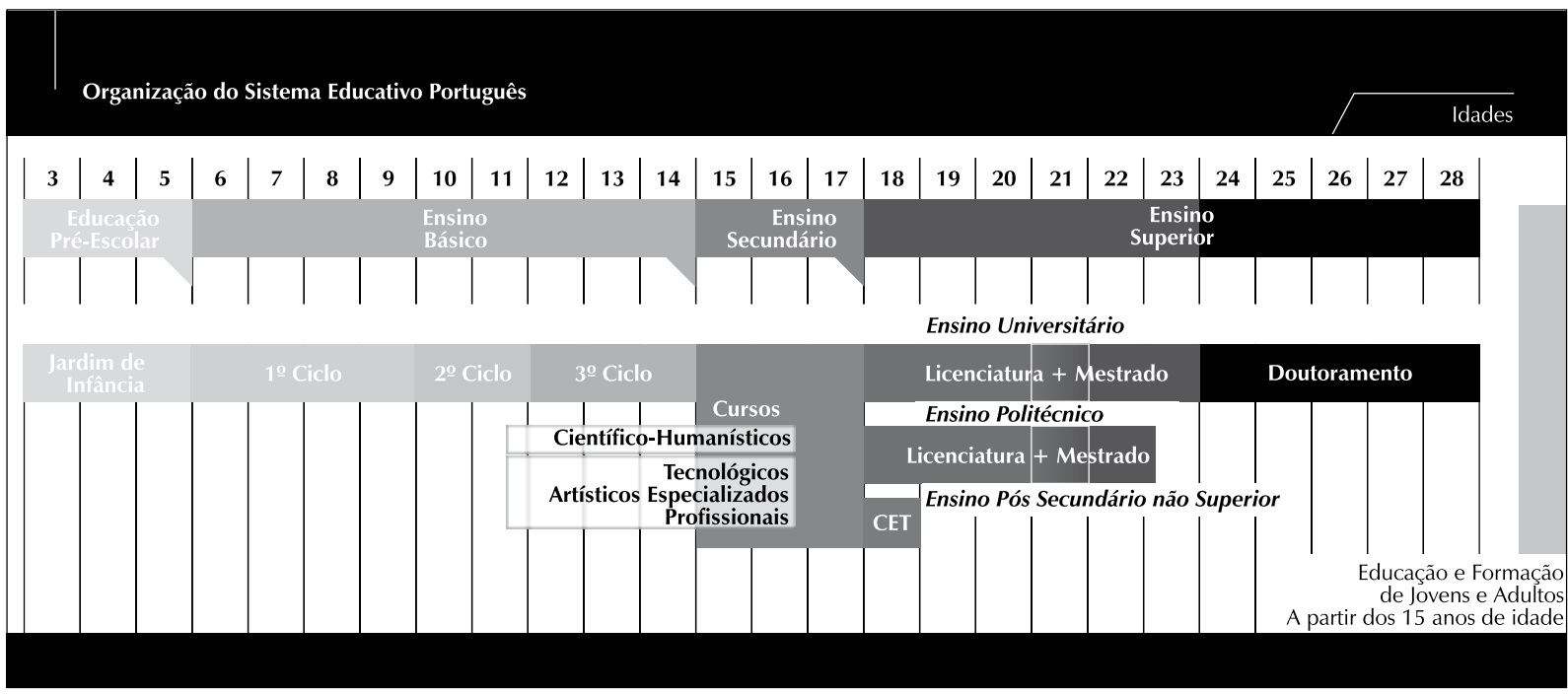

Fonte: disponível em: $<$ http:www.gepe.min-edu.pt $>$. 
Fátima Antunes e Virgínio Sá

Estado, escolas e famílias: públicos escolares e regulação da educação

O texto apresenta alguns resultados de uma investigação recentemente concluída que, genericamente, se inscreve nos complexos processos de (multi)regulação da educação. O estudo desenvolveu-se num concelho do norte de Portugal (convencionalmente designado Vila Formosa), circunscrevendose às escolas com oferta de ensino secundário. A análise dos dados sugere que, na topografia complexa dos processos de (multi)regulação do campo escolar, a combinação de medidas de política educativa com recursos e cursos de acção que as diferentes escolas e as diversas categorias de famílias e jovens detêm e adoptam constituem uma tríade de fontes de dinâmicas, umas vezes convergentes, outras vezes em tensão que, por seus efeitos sociológicos cumulativos, geram a reordenação do campo de lutas concorrenciais em torno da educação, lutas essas 
que parecem penalizar sobretudo as famílias que já sofrem de outras desvantagens.

Palavras-chave: (multi)regulação da educação; públicos escolares; políticas de escolha; explicações; lutas concorrenciais.

State, schools and families: school publics and regulation of education

The text presents some results of a recently concluded investigation that, generically, is part of the complex processes of the (multi) regulation of education. The study was developed in a district in the north of Portugal (conventionally designated Vila Formosa) and was limited to schools that offered secondary education. The analysis of the data suggests that, in the complex topography of the processes of (multi)regulation of the school field, the combination of measures of educational policy with resources and courses of action that the different schools and the diverse categories of families and young people possess and adopt constitute a triad of dynamic sources, sometimes convergent and sometimes tense, that, by their cumulative sociological effects, generate the re-ordination of the field of competing struggles in education that seem to penalize, above all, the families that already suffer other disadvantages.

Key words: (multi)regulation of education; school publics; policies of choice; explanations; competing struggles

\section{Estado, escuelas y familias:}

\section{públicos escolares y regulación de la} educación

El texto presenta algunos resultados de una investigación recientemente finalizada que, genéricamente, se inscribe en los complexos procesos de (multi) regulación de la educación. El estudio se desarrolló en un consejo del norte de Portugal (asignado convencionalmente Vila Formosa), circunscribiéndose a las escuelas con oferta de enseñanza secundaria. El análisis de los datos sugiere que, en la compleja topografía de los procesos de (multi)regulación del campo escolar, la combinación de medidas de politica educativa con los recursos y los cursos de acción que las diferentes escuelas y las diversas categorías de familias y jóvenes retienen y que adoptan, constituyen una tríada de fuentes de dinámicas, unas veces convergentes, otras veces en tensión que, por sus efectos sociológicos acumulativos, generan la reordenación del campo de luchas competitivas alrededor de la educación y de los resultados de esas luchas que parecen penalizar principalmente a las familias que ya sufren de otras desventajas.

Palabras clave: (multi)regulación de la educación; públicos escolares; politicas de elección; explicaciones; luchas competitivas 